\title{
Theory, Experience and Practice
}

\begin{tabular}{|r|l|}
\hline Journal: & Journal of Evaluation in Clinical Practice \\
\hline Manuscript ID & JECP-2016-0226 \\
\hline Wiley - Manuscript type: & Personal View \\
\hline Date Submitted by the Author: & $24-$ May-2016 \\
\hline Complete List of Authors: & $\begin{array}{l}\text { Loughlin, Michael; MMU Cheshire, Interdisciplinary Studies } \\
\text { Fuller, Jonathan; University of Toronto, Faculty of Medicine } \\
\text { Bluhm, Robyn; Michigan State University, Philosophy } \\
\text { Buetow, Stephen; University of Auckland, General Practice and Primary } \\
\text { Health Care } \\
\text { Borgerson, Kirstin; Dalhousie University, Philosophy }\end{array}$ \\
\hline Keywords: & \begin{tabular}{l} 
philosophy of medicine, experience, healthcare, epistemology, evaluation \\
\hline Abstract:
\end{tabular} \\
\hline $\begin{array}{l}\text { Despite its potential hazards, the activity of questioning theoretical } \\
\text { frameworks and and proposing solutions is necessary if progress is even to } \\
\text { be possible. Intellectual history has by no means ended so we cannot } \\
\text { expect to have all the answers, and from time to time the activity of critical } \\
\text { questioning will be frustrating. But intellectual progress requires us to } \\
\text { continue the process of asking fundamental questions. The alternative to } \\
\text { thinking in this way is indeed unthinkable. }\end{array}$ \\
\hline
\end{tabular}


Title: Theory, experience and practice

Subtitle: Philosophy Thematic Edition 2016: Editorial Introduction

\author{
Authors: \\ Michael Loughlin PhD, Professor of Applied Philosophy, Department of Interdisciplinary \\ Studies, MMU Cheshire, Crewe, UK \\ Jonathan Fuller, MD/PhD student, Faculty of Medicine, University of Toronto, Ontario, Canada \\ Robyn Bluhm PhD, Associate Professor, Department of Philosophy, Michigan State University, \\ East Lancing, Michigan, USA
}

Stephen Buetow PhD, Associate Professor, Department of General Practice, University of Auckland, Auckland, New Zealand

Kirstin Borgerson MA PhD, Associate Professor, Department of Philosophy, Dalhousie University, Halifax, Nova Scotia, Canada

Correspondence: Professor Michael Loughlin, MMU Cheshire, Crewe CW1 5DU, m.loughlin@mmu.ac.uk

Keywords: Medicine, healthcare, philosophy, epistemology, ethics, metaphysics, ontology, disease, health, classification, clinical reasoning, value, evidence-based medicine, patientcentred, person-centred

\begin{abstract}
Despite its potential hazards, the activity of questioning theoretical frameworks and proposing solutions is necessary if progress is even to be possible. Intellectual history has by no means ended, so we cannot expect to have all the answers, and from time to time the activity of critical questioning will be frustrating. But intellectual progress requires us to continue the process of asking fundamental questions. The alternative to thinking in this way is indeed unthinkable.
\end{abstract}

\title{
Introduction
}

It is easy for those of us who work in education to see the value of thinking, including explicit theorising about questions of fundamental importance. In previous thematic editions of this journal, we have argued that the practice of critical thinking is of fundamental importance if virtue, progress and more enlightened practices are to be possible. [1-3] Without populations - in the workplace and in society generally - able to expose underlying assumptions that frequently frame popular debate, we are at the mercy of the spin-doctors and opinionmanagers who have made the control of human behaviour their explicit goal. [4-7] In populations governed by the principle of 'moderate anti-intellectualism' [1] people are encouraged to think about 'how-to' questions - how to accomplish certain tasks, to apply established rules, guidelines and theoretical frameworks in particular situations and to achieve pre-determined goals. But underlying, 'why' questions - about the justification for the goals, the intellectual basis for the rules and guidelines as opposed to possible alternatives are dismissed as impractical. In a world in which we are constantly bombarded with bad arguments, inadequate rationalisations and rhetorical ploys to make us conform to unquestioned norms, [7] it makes very little sense to talk of such a population as containing autonomous people - meaning persons who think for themselves and are in full, rational control of their own actions. [6,7]

However, there are also serious concerns about the potential damage theorising can do. If employed in the wrong ways, theorising can either serve to undermine the common-sense knowledge of practitioners and patients, deny truths that would otherwise be intuitively obvious or cause us to be sceptical in situations where in fact trust would be the more beneficial, more human reaction.[6,8-10] The view that theory should, in some sense be 'grounded in' experience would command very broad support, as would the claim that a key 
goal of theory is to produce conclusions that facilitate more effective practice. But these broad claims would be supported by defenders of radically different views about the proper basis of practice,[3] from authors with a 'positivist' approach to evidence and clinical reasoning [11-14] to defenders of phenomenological approaches to reasoning in practice. $[15,16]$ Even the view that medicine should be more 'person-centred' can be conceptualised and justified in a variety of - potentially incompatible - ways [17], as some of the contributions to this edition strikingly demonstrate.

In this thematic edition of the Journal of Evaluation in Clinical Practice, we present a range of papers that raise questions or problems about not only the intellectual basis for practice, but also about the dangers inherent in theorising about practice - the sense that the wrong sort of theorising can actually be harmful. Such questions are sometimes characterised as matters of 'philosophical methodology' in that they express concerns about how we go about addressing important, underlying questions if we are to say something actually helpful to practitioners and patients. Contributors present different views about the sort of thinking we need when discussing questions of ethics, knowledge and reasoning in clinical practice - reflecting radically different views of what it means to have a basis for practice, and why one should need such a thing in the first place.

\section{Thinking as a way of challenging or conforming to 'the norm'}

The edition begins with a debate about the assumptions not only of medical ethics but of the very activity of theorising about morality, at least as such theorising has typically been conducted for much of our intellectual history. [18-20] Joel Backström and Hannes Nykänen [18] note that, from the development of the Hippocratic Oath to current debates about bioethics and values-based practice, $[21,22]$ a "dominant conception that morality is a matter of values and valuation" is typically treated as self-evident. The authors claim that this conception encourages us to ignore a fundamental truth about the nature of moral experience. It effectively represses conscience, the fundamental importance of what they characterise as the "I-you" relationship. They argue that all moral theories - including Kantian and utilitarian theories and even approaches based on the concept of virtue - serve to codify and reinforce dominant ideas in society, encouraging us to ignore our moral experience and internalise collective values or dispositions. Moral relativism and moral particularism are seen as responses to this dominant conception that fail to escape its underlying assumptions.

In his response, [19] Stephen Buetow tries to work out the implications of this critique of moral theorising for practical debates about healthcare, developing implications of Backström and Nykänen's argument and interrogating the meaning of some of their key claims. He applauds their defence of conscience and notes their warnings about "non-reflectively identifying with the collective values of society" at a time when concern is growing that, "rather than relate to themselves and patients as persons, clinicians embrace anonymized, normative demands of group values." He welcomes the analysis because it helps to explain what he regards as the "rising depersonalization in health care, lack of resistance to this development and a need to revitalize person-centred health care." However, he rejects what he sees as a false dichotomy in their work between 'conscience' on the one hand and both 'value' and 'virtue' on the other. For Buetow, commitment to conscience is still compatible with "constructing personcentred care as a virtue ethic nourishing authenticity and reciprocated caring". We should not so much be jettisoning such concepts as 'virtue' and 'value' (he is not sure how we could) as noting the possible dangers in their (mis)use.

In their counter-response,[20] the authors reiterate their fundamental points that "conscience is a concern for people, in the sense of an 'l' to a 'you', not for values, beliefs, norms, principles, etc" and that dominant, "value $\square$ based ethics is a repression (ie self $\square$ deceptive denial and evasion) of conscience". Referring to examples and the history of moral philosophy, they note that: "The problems in different versions of value $\square$ ethics are legion," and "proponents of various positions - Kantians, consequentialists, virtue $\square$ ethicists, etc. have managed to shoot their opponents full of holes, so that no man remains standing." They regard their critique as a major challenge to theoretical arguments that have shaped our conception not only of medical ethics but of moral thinking more generally for centuries, so they expect Buetow - and perhaps many others - to struggle in getting to grips with its implications. 
Certainly such a broad critique of moral theories will lead some to wonder what role, if any, moral theory can have in informing practice. Backström and Nykänen seem to ascribe all ideas about value, virtue and principle to the role of 'repression', while Buetow wants to stress that these ideas can form part of more defensible conceptions of ethics - though he agrees with them that all such ideas, like their own favoured idea of 'conscience', can in fact be abused to form rationalisations for clearly immoral acts. While value-theory can function simply to reinforce non-rational norms/consensus, for him this is not an essential characteristic of such theories. The history of philosophical debate in this area has not ended with all the major approaches effectively refuting each other. Rather, it is on-going, and the major traditions, precisely through their radical differences, have all brought out important aspects of moral thinking - and part of the exercise of good conscience is in weighing the significance of these aspects in making decisions in particular cases.

The section continues with a paper whose subject matter and methodology are strikingly different from the approaches of those papers already mentioned, and yet whose conclusions resonate with that debate. Focussing specifically on medical decision-making, Michael Morreau and Aidan Lyon use a multi-agent computer simulation of groups of physicians to test the assumption that common standards lead to better decision-making. [23] The standards, in this case, are epistemic and concern deliberation in groups and the use of scores and grades in evaluation. The authors note that: "One might expect individual differences in members' grading standards to reduce the capacity of the group to discover the facts on which wellinformed decisions depend." However, their observations of the simulated groups suggest that: "on the contrary... this kind of diversity can in fact be conducive to epistemic performance. Sometimes, it is adopting common standards that may be expected to result in poor decisions." This conclusion resonates with recent arguments in support of social and cognitive diversity, [24] and explanatory pluralism. [25]

Utilsing Longino's arguments about the centrality of diversity and public critique within a community of scientists, [26] Emily Bingeman applies Longino's criteria for assessing the objectivity of a knowledge-productive community to assess Evidence-based Medicine (EBM) against a casuistic framework for medical knowledge. [27] She argues that "EBM's strict adherence to a hierarchical organization of knowledge can reasonably be expected to block it from fulfilling a high level of objectivity." In contrast, she claims that a casuistic framework "could be expected to better facilitate a more optimal epistemic community," because it emphasizes critical evaluation in conjunction with the flexibility of a case-based approach.

\section{Medical concepts and reality}

Does involvement in the practice of medicine commit us to any particular set of philosophical assumptions about the world and our place within it? If so, are those assumptions open to criticism and what implications for practice might such criticisms have? Anna Louise Kirkengen and colleagues [28] argue that contemporary medicine's perception of reality is theoretically loaded in ways that may once have served the interests of progress in specific areas, but which now stand in its way. Current medical knowledge, they maintain, ignores central tenets of human existence, notably the physiological impact of subjective experience, relationships, history, and sociocultural contexts. While the "materialistic shift of enlightenment philosophy" was at one point crucial to progress in medicine and "yielded astonishing results", contemporary medicine now faces problems that cannot be solved (or indeed properly characterised, let alone understood) by "more of the same". They conclude that the biomedical framework now needs radical revision: "we must acknowledge that health, sickness and bodily functioning are interwoven with human meaning-production, fundamentally personal and biographical."

In contrast, Seth Joshua Thomas [29] sets out to defend evidence-based healthcare against the claim that it it is committed to a particular, 'reductionist' world view and to question the philosophical commitments of some of its critics. Focussing on the claim that an "emphasis on the hierarchy of evidence, grounded in the use of randomized controlled trials" embodies a philosophical commitment to a "modernist" conception of reality, Thomas disputes the apparent implication that the approaches to healthcare he identifies as "evidence-based" inevitably "fail to recognize the patient as the complex self she is, treating her instead as merely a quantifiable, medical-scientific object." For Thomas, a purely scientific method is "in principle neutral with regard to questions of selfhood", so there can simply be no question of a 
philosophical tension between evidence-based and person-centred approaches, and no need for the sort of 'philosophical overhaul' called for by other contributors to this edition.

The view that scientific reasoning can indeed embody significant philosophical commitment is taken seriously by Daniele Chiffi and Renzo Zanotti. [30] Presenting examples from clinical reasoning, these authors explore the epistemological and metaphysical commitments in perspectives on clinical possibility. They note that modal concepts are widely used in clinical reasoning, but philosophical debate on such notions is still at an initial stage. Opening up what they regard as an important new line of research in the philosophy of healthcare, they argue that almost all clinical possibilities are potentialities: "that is, possibilities that may be actualised by effective, appropriate and feasible interventions" and they introduce "some basic views on the nature of possibility, showing their validity and limitations when applied to the concept of clinical possibility." Their discussion is followed by a contribution from Matthew Mercuri and Brian Baigrie, [31] which examines the use of epidemiological risk information as evidence of causation in medical court cases. They illustrate various standards of evidence including statistical significance, relative risks (RRs) that are greater than 2, and biological plausibility - through the case of Goodman v. Viljoen, a medical malpractice suit. They find that multiple kinds of evidence were brought to bear in establishing individual causation, and find analogies as well as disanalogies between the legal context and the clinical context when using risk information to make causal attributions or predictions.

In addition to philosophical commitments concerning the nature of possibility and causation, medical reasoning also raises questions of ontological commitment with regard to the nature of disease. [32] Such questions are particularly pressing in the area of psychiatry. As Sam Fellows notes: "Validity of psychiatric syndromes is typically associated with questions over their reality." [33] Fellows argues that Kendell and Jablensky's account of validity - which links the validity of a syndrome to its causation by a specific biological mechanism not present in other syndromes - is overly restrictive. He argues that: "Scientific phenomena are the product of a multiplicity of unstable overlapping causes but this does not mean our descriptions of scientific phenomena are automatically arbitrary." Rather, he claims, science deals with multiple unstable causes by producing idealised models that can be "approximately true".

Returning to the crucial questions about contemporary medical ontology raised by Kirkengen et al [28], and building on her important discussion of 'metaphysical care' and the ontology of disease in the previous philosophy thematic edition of this journal, [32] Alexandra Parvan attempts to lay philosophical foundations for person-centred healthcare. [34] While Parvan would clearly agree with Kirkengen and colleagues that contemporary biomedicine needs to rethink its theoretical basis, her own analysis of current medical thinking is somewhat different from theirs, as is her own recipe for a genuinely humanistic, person-centred approach to care. Going back to ancient philosophical views of disease as 'bounded entity' or as 'relation', Parvan proposes a way to think ontologically about disease "that places it in necessary connection with the patient as person", drawing on Augustine's views on disease, bodily integrity, and the human person as mind-body unit.

Ramesh Prasad [35] asks what determines the 'ownership' of human body parts, looking in particular at cases of transplantation where the biological integrity of the whole person is disrupted. He makes the distinction between "internal" and "external property" and claims that "Poor outcomes in some types of kidney donors may be due not only to a failure in their proper selection by standard medical testing or post-donation care, but may also be a manifestation of differing effects on sense of self resulting from transfer of their internal property." In contrast to dopamine levels that altruistic behaviour increases, commercial donation may produce cortisol or adrenergic-based responses because the brain interprets the donation as traumatic in the absence of a concurrent feeling of reward. Thus, there may be a cognitive basis to society's antipathy to commercial kidney transplantation. If screening rules that treat a kidney as external property are inadvertently harming some living donors, a property transfer approach, informed by a careful cognitive assessment, could help to regulate harm associated with neurocognitive changes in the donors.

The section concludes with David Misselbrook's insightful and engaging discussion of the ontology of health and the goals of medicine. [36] Utilising ideas taken from the very different philosophies of Aristotle and Hume, Misselbrook presents an analysis of contemporary debates about naturalist, biostatistical and normative accounts of health and disease and defends an Aristotelian conception of 'human flourishing' as a key goal for medical practice. 
Like all good examples of applied philosophy, his paper makes underlying philosophical questions highly accessible and uses the problems of practice to raise questions that challenge distinctions operating in mainstream academic philosophical debate.

\section{Medical Epistemology: expertise, paternalism, diagnosis and bias}

Theoretical questions about the nature of knowledge seem inescapable for defenders of any approach to clinical reasoning and practice, be they exponents of EBM, or indeed of patientor person-centred care. In the context of continued debates about the future of EBM, [37,38] Rudolfo Gaeta and Nelida Gentile [39] use epistemology and Kuhn's philosophy of science to present a conception of EBM as a 'meta-methodology". Insofar as the development of EBM as a movement represented a genuinely new alternative in the field of medicine, showing a way in which the discipline would henceforth endure, the authors show that it could not have been what Kuhn meant by a 'paradigm', but this potentially reflects the problems with Kuhn's philosophy as much as it reflects any identity-crisis in EBM.

Motivated in the first instance by the problem that gave rise to Parvan's analysis, [32,34] that of patient non-adherence to physicians' recommendations, Mary-Clair Yelovich [40] develops a thesis on the nature and limits of expertise that provides "a new epistemological framework that recognizes legitimate knowledge offered by the patient as well as the physician." By treating the clinical encounter not only as "an encounter between persons" [41] but as a meeting of experts, Yelovich develops a "patient expertise framework within the paradigm of patient-centred medicine". Assuming the goal of medical treatment to be alleviation of suffering, patient expertise becomes centralized as a means of determining the nature of patient suffering. Drawing on ideas clearly at work in the paper by Kirkengen et al, [28] Yelovich identifies two aspects of the patient's tacit knowledge: the body aspect and the meaning aspect, both of which, she notes, are context-dependent and directly accessible only to the patient. She notes that both are "recognised as essential to the success of the interaction", and clearly distinguished from the equally essential expertise of the clinician. She argues in detail the practical advantages of this approach for the problem she set out to address.

In stark contrast, the contribution by Anthony Fry and Tania Gergel [42] looks at the need for paternalism in clinical practice, when the conditions for the sort of patient-centred approach Yelovich outlines do not obtain. In a paper presented to the workshop on Paternalism and Trust at Kings College London, reported in the previous philosophy thematic edition of JECP, [43] the authors discuss a case where paternalism seems appropriate. Factitious Disorder (FD) is usually classified as a mental disorder involving deliberate and hidden feigning or inducement of illness, in order to achieve patient status. (In such a case, it is hard to know what to make of the concept of patient expertise.) Looking at case histories, the authors argue that there are no compelling reasons for rejecting the use of paternalistic interventions for FD, but that further investigation of FD and frameworks for psychiatric paternalism, in relation to FD and other mental disorders, are urgently needed.

Noting that diagnosis is "arguably the cornerstone of medicine", Ashley Kennedy attempts to to "extend the work that Worrall and Cartwright have done on the evaluation of medical treatments to the topic of medical diagnosis." [44] Much has been written on the role of randomized controlled trials and mechanistic reasoning in the evaluation of therapeutic treatments, but the question of how diagnostic tests and procedures should be evaluated is surprisingly under-theorised. Kennedy begins by addressing a series of questions about accuracy, effectiveness and value, noting that diagnostic value extends beyond patient outcomes.

Wendy Rogers and Yishai Mintztker [45] look at the problem of overdiagnosis, when diagnosis does not benefit the patient because the condition diagnosed is not a harmful disease in those patients. Looking at a range of examples, from cancer screening to attention deficit hyperactivity disorder, they classify two different types of overdiagnosis.

Misclassification overdiagnosis arises because the diagnostic threshold for the disease (they give the illustration of chronic kidney disease) has been set at a level where many people without harmful disease are nonetheless diagnosed. Maldetection overdiagnosis arises because, at the time the diagnosis is made and despite the presence of a 'gold standard' diagnostic test, it is not possible to discriminate between harmful and non-harmful cases of the index disease - they give the example of thyroid cancer. Like the paper by Fry and 
Gergel, this one proposes that the first stage for addressing the problem is to develop an adequate conceptual analysis.

Donald Stanley and Daniel Campos [46] investigate logical strategies for narrowing the list of diagnostic hypotheses during the diagnostic process, including Bayesian confirmation theory, frequentist statistics and inference to the best explanation. They discuss these strategies in the context of six realistic clinical cases, showing how informal clinical reasoning can be understood as instances of these confirmation theories that are familiar to philosophers of science. Stanley and Campos ultimately argue for using the full range of inferential strategies available rather than limiting diagnostic reasoning to just one approach.

Matthew Maddocks and colleagues [47] discuss problems in 'placebo-controlled' physiotherapy trials and how the use of inadequate placebos can lead to systematic bias, sometimes underestimating and sometimes overestimating the treatment effect. They adopt Grünbaum's classic definition of a placebo, which has: all of the incidental features of the treatment, none of the characteristic features, and nothing more. They use three published physiotherapy trials that may have suffered from bias due to an inadequate placebo control to illustrate how failure to satisfy Grünbaum's criteria might account for biased estimation of the treatment effect, and argue that because of the difficulty of constructing placebos in physiotherapy trials it is often necessary to use other trial designs.

\section{Phenomenological approaches}

As noted in our opening comments, for many authors the only adequate 'base' for theorising about practice is in lived experience: we do not understand health and illness, or the purpose and nature of healthcare, unless we ground that understanding in the everyday experience of those who have to live with the problems we aim to address. [15,16] This section includes papers that attempt to illustrate the uses of phenomenology in the discussion of healthcare.

Juan Borda [48] discusses the relationship between Bipolar Disorder (BD) and Borderline Personality Disorder (BPD). Despite intense debate for two decades, current diagnostic classifications approach this complex phenomenon using syndromatic definitions based on presence or absence of a restricted set of signs or symptoms which have demonstrated low specificity. Borda argues that the phenomenological method in psychiatry can complement other approaches, helping identify differences between two separated clinical syndromes. Borda sets out to explore one particular clinical difference between these two conditions: the experience of self-continuity and time perception. While BPD patients tend to experience only the present, BD patients are constantly worried about the contradictions in their past experiences, and the latent risk of losing control of themselves in future episodes of their disease. This contrast needs to be corroborated in future research comparing directly the two groups in terms of the continuity of the self and their temporal structures.

Ines Hipolito [49] discusses the phenomenology of intersubjective impairment, in a paper that attempts to show that "the second-person perspective" can be used to point out particular features of social cognition and its related psychopathology. Characterising the secondperson perspective as "the congruence point between an objective process and the subjective experience," Hipolito tries to explain schizophrenia as a self-related deficit, first in the light of the first- and the third-person perspective; and afterward, in the light of the currently less understood second-person perspective.

Drawing on psychiatric literature and philosophical work on self-knowledge, Jordi Fernandez and Suzanne Blis [50] discuss how schizophrenia affects a subject's sense of self. They consider experience of alienation of mental states and actions and propose that the experience of thoughts, feelings, impulses and actions as not being one's own is the experience of not being able to find reasons in support of occupying those states. To make sense of these phenomena they propose two components to our normal sense of self, understanding schizophrenia with reference to the dissociation of these components.

\section{Debates}

This year's debates section contains two responses to previously published articles in this journal. Responding to Alexandra Parvan's paper in the previous philosophy thematic [32] on patients' "substantialisation of disease" and metaphysical care, Thor Erik Eriksen and Anna Luise Kirkengen [51] begin by providing their own reflection on the epistemological and 
ontological questions raised by the phenomenon of medically unexplained symptoms or syndromes(MUS). They argue that "such health challenges can serve as the basis for an exploration of how the suffering person as well as the medical caretaker come to grips with disease, incapacitation or suffering." While they broadly welcome and support Parvan's efforts "to provide a renewed language as regards human suffering", they fear she has given too much ground to biomedical ontology and epistemology: "when, for example, she perpetuates the prevailing biomedical concepts of the doctors' role as knowers and the patients' role as adaptors." In support of this point they cite her language of "non-adherence" - matched with the idea of clinicians being the suppliers of "metaphysical care". Their own account of the phenomenon Parvan terms "substantialisation" (for which they prefer the term "thingification") describes "a process wherein patients reify their suffering in order to meet their doctors on equal terms, which carries a potential for alienation." Whether we are patients or practitioners, we need a new philosophical framework if we are to avoid the problems Parvan's paper highlighted.

Reading both this commentary and Parvan's contribution to this thematic, [34] we feel these authors' differences are less significant than their similarities, and we look forward to further productive exchanges on these vital underlying questions: about how we conceptualise health, illness, suffering and ultimately ourselves. As noted in our opening comments, the wrong theoretical assumptions can indeed stand in the way of progress, and these authors are to be praised for questioning underlying conceptions that may strike many as "sheer common sense", given our current, dominant conceptions of the world and our place within it.

The edition concludes with a commentary by Michael Loughlin, Peter Wyer \& Sandy Tanenbaum, [52] in reply to an article by Milos Jenicek [53] in last year's EBM-thematic edition of this journal. Responding to the 'crisis' for EBM identified by prominent contributors to the debate, $[37,38]$ Jenicek proposed a "new medical cognitive science" that would "supplement" EBM with certain "gnostic or epistemological processes" to address what he sees as a deficit in EBM's approach to clinical reasoning.[53] While Loughlin and colleagues find Jenicek's paper fundamentally confused, they nonetheless regard it as an extremely helpful contribution. They explain this apparently paradoxical assessment by noting there are fundamental epistemological questions regarding EBM that remain unaddressed. While some commentators seem happy to brush over vital questions about EBM's intellectual heritage, taking little note of the distinction between empiricist and rationalist approaches to medical epistemology, [29] Loughlin et al regard an accurate account of this heritage as vital to understanding the current EBM debate and to the possibility of making serious intellectual progress in this area. They argue that Jenicek effectively attempts to 'supplement' an empiricist framework with a rationalist conception of reasoning, and this amounts to a philosophically untenable project. However, the attempt to reconcile these opposed epistemic traditions, to find something worthwhile in each of them, (much like the effort to reconcile opposing ethical traditions discussed in our opening sections) may well turn out to be the way forward for medical epistemology:

'the failure of [Jenicek's] identified 'approaches' to 'interconnect' requires us to give more explicit attention to the underlying epistemological assumptions that frame the EBM debate. While we think he fails to solve the problem he identifies, that failure can, in itself, teach us something about its fundamental nature. There are times when proposing a confused solution to a problem is a better way to move a debate forward than simply insisting that there is nothing to feel confused about."

This point seems pertinent with regard to our opening comments about the activity of theorising. Despite its potential hazards, the activity of questioning theoretical frameworks and and proposing solutions is necessary if progress is even to be possible. Intellectual history has by no means ended $[54,55]$ so we cannot expect to have all the answers, and from time to time the activity of critical questioning will be frustrating. But intellectual progress requires us to continue the process of asking fundamental questions. The alternative to thinking in this way is indeed unthinkable.

\section{References}


[1] Loughlin, M, Upshur, R, Goldenberg, M, Bluhm, R, \& Borgerson, K (2010) Editorial introduction and commentary: 'Philosophy, Ethics, Medicine and Health Care: the urgent need for critical practice', Journal of Evaluation in Clinical Practice 16 (2) 249-59

[2] Loughlin, M, Bluhm, R, Buetow, S, Goldenberg, MJ, Upshur, R, Borgerson, K \& Entwistle, V (2011) Virtue, Progress and Practice, Journal of Evaluation in Clinical Practice, 17:5, 839846

[3] Loughlin, M, Bluhm, R, Buetow, S, Goldenberg, M, Upshur, R, Borgerson, K, Entwistle, V \& Kingma, E (2012) Reason and Value: making reasoning fit for practice, Journal of Evaluation in Clinical Practice, 18:5, 929-39

[4] Orwell, G 'Politics and the English Language' in Carey,J (ed.) (2002) George Orwell: Essays. Everyman's Librarly, London, 954-67

[5] Poole, S (2006) Unspeak. Little, Brown. London

[6] Loughlin, M (2002) Ethics, Management and Mythology. Radcliffe Medical Press, Oxon

[7] Loughlin M. (2010) Argument, platitude, caricature \& ridicule in the EBM debate [Talk delivered 13April 2010 at Manchester Metropolitan University, UK] Available at https://www.youtube.com/watch?v=Khl7POgCneY [Accessed 1 April 2016]

[8] O’Neill, O (2002) Autonomy and Trust in Bioethics, Cambridge University Press, Cambridge

[9] Pellegrino, E. D., R. M. Veatch and J. P. Langan (eds.) (1991 Ethics, Trust and the Professions: Philosophical and Cultural Aspects, Washington, DC: Georgetown University Press

[10] Moore, GE (2014) 'A Defence of Common Sense' in Philosophical Papers, Routledge, Abingdon

[11] Carnap, R. (2011) The Unity of Science. Oxon: Routledge.

[12] Schlick, M. (1979) Moritz Schlick: Philosophical Papers, Volume II (1925-1936). Amsterdam, Netherlands: Springer

[13] White, K. \& Willis, E. (2002) Positivism resurgent: the epistemological foundations of evidence-based medicine. Health Sociology Review, 11, 5-15.

[14] Djulbegovic, B., Guyatt, G. H. \& Ashcroft, R. E. (2009) Epistemologic inquiries in evidence-based medicine. Cancer Control, 16, 158-168

[15] Carel, H. (2008) Illness, Acummen, Durham

[16] Mitchell, D (2012) Everyday Phenomenology, Cambridge Scholars Publishing, Newcastle upon Tyne

[17] Loughlin, M. (2014) What person-centered medicine is and isn't: Temptations for the 'soul' of PCM. European Journal for Person Centered Healthcare, 2(1), 16-21

[18] Backström, J. and Nykänen, H. (2016), Collectivity, evil and the dynamics of moral value. Journal of Evaluation in Clinical Practice 22:4

[19] Buetow, S. (2016), Morality is about values and character. A commentary on Backström and Nykänen (2016). Collectivity, evil and the dynamics of moral value. Journal of Evaluation in Clinical Practice 22:4

[20] Backström, J., \& Nykänen, H (2016) Ethics: the perfect mix? Response to Buetow. Journal of Evaluation in Clinical Practice 22:4

[21] Fulford, K. W. M. (2011) The value of evidence and evidence of values: bringing together values-based and evidence-based practice in policy and service development in mental health. Journal of Evaluation in Clinical Practice, 17 (5), 976-987.

[22] Loughlin, M (ed.) (2014) Debates in Values-Based Practice: Arguments For and Against, Cambridge University Press, Cambridge

[23] Morreau, M \& Lyon, A (2016) How common standards can diminish collective intelligence: a computational study Journal of Evaluation in Clinical Practice 22:4 
[24] Page, S (2008) The Difference. Princeton University Press

[25] Longino, H (2013) Studying human behaviour: How scientists investigate aggression and sexuality. Chicago: University of Chicago Press

[26] Longino, H. (1998) Values and Objectivity. In M. Curd, J.A. Cover \& C. Pincock (Eds.) Philosophy of Science: The Central Issues (2nd ed.)(p.p. 144-164). New York, NY:W.W. Norton \& Company

[27] Bingeman, E.(2016) Evaluating normative epistemic frameworks in medicine: EBM and casuistic medicine. Journal of Evaluation in Clinical Practice 22:4

[28] Kirkengen, A. L., Ekeland, T.-J., Getz, L., Hetlevik, I., Schei, E., Ulvestad, E. and Vetlesen, A. J. (2016) Medicine's perception of reality - a split picture: critical reflections on apparent anomalies within the biomedical theory of science. Journal of Evaluation in Clinical Practice 22:4

[29] Thomas, S (2016) Does Evidence-Based Health Care Have Room for the Self? Journal of Evaluation in Clinical Practice 22:4

[30] Chiffi, D. and Zanotti, R. (2016), Perspectives on clinical possibility: elements of analysis. Journal of Evaluation in Clinical Practice 22:4

[31] Mercuri,M \& Baigrie,B (2016) Interpreting Risk as Evidence of Causality: lessons learned from a legal case to determine medical malpractice. Journal of Evaluation in Clinical Practice 22:4

[32] Parvan, A. (2014) Patients' substantialization of disease, the hybrid symptom and metaphysical care. Journal of Evaluation in Clinical Practice, 21:3, 380-88

[33] Fellowes, S (2016) A reappraisal of Kendell and Jablensky's account of validity. Journal of Evaluation in Clinical Practice, 22:4

[34] Parvan, A (2016) Monistic Dualism and the body electric: an ontology of disease, patient and clinician for person-centred healthcare. Journal of Evaluation in Clinical Practice, 22:4

[35] Prasad,R (2016) Distinguishing Internal Property from External Property in Kidney Transplantation. Journal of Evaluation in Clinical Practice, 22:4

[36] Misselbrook, D. (2016), Aristotle, Hume and the goals of medicine. Journal of Evaluation in Clinical Practice 22:4

[37] Greenhalgh, T., Howick, J. \& Maskrey, N. (2014) Evidence based medicine: a movement in crisis? British Medical Journal, 348 (g3725), 1-7.

[38] Every-Palmer, S \& Howick, J (2014) How evidence-based medicine is failing due to biased trials and selective publication, Journal of Evaluation in Clinical Practice, 20:6, 908914

[39] Gaeta, R. and Gentile, N. (2016), Evidence, discovery and justification: the case of evidence-based medicine. Journal of Evaluation in Clinical Practice. 22:4

[40 ] Yelovich, M-C. (2016) The patient-physician interaction as a meeting of experts: one solution to the problem of patient non-adherence. Journal of Evaluation in Clinical Practice, $22: 4$

[41] Henry, S.G. (2006) Recognizing Tacit Knowledgein Medical Epistemology. Theoretical Medicine and Bioethics, 27(3), 187-213

[42] Fry, A. and Gergel, T. L. (2016), Paternalism and factitious disorder: medical treatment in illness deception. Journal of Evaluation in Clinical Practice, 22:4

[43] Bullock, E, Gergel, T \& Kingma, E (2015) Interdisciplinary workshop in the philosophy of medicine: Parentalism and Trust, Journal of Evaluation in Clinical Practice, 21:3, 542-8

[44] Kennedy, A. G. (2016) Evaluating diagnostic tests. Journal of Evaluation in Clinical Practice, 22:4

[45] Rogers, W. A., and Mintzker, Y. (2016) Getting clearer on overdiagnosis. Journal of Evaluation in Clinical Practice, 22:4 
[46] Stanley, D. E. and Campos, D. G. (2016) Selecting clinical diagnoses: logical strategies informed by experience. Journal of Evaluation in Clinical Practice, 22:4

[47] Maddocks,M, Kerry,R, Turner, A \& Howick,J (2016) Problematic placebos in physical therapy trials. Journal of Evaluation in Clinical Practice, 22:4

[48] Borda, J. P. (2016) Self over time: another difference between borderline personality disorder and bipolar disorder. Journal of Evaluation in Clinical Practice, 22:4

[49] Hipólito, I (2016) The phenomenology of intersubjective impairment. Journal of Evaluation in Clinical Practice, 22:4

[50] Fernández, J and Blis, S (2016) Schizophrenia and the Estranged Self Journal of Evaluation in Clinical Practice, 22:4

[51] 2. Eriksen, T. E. and Kirkengen, A. L. (2016) Patients' 'thingification', unexplained symptoms and response-ability in the clinical context: in response to 'Patients' substantialization of disease, the hybrid symptom and the metaphysical care', by Alexandra Parvan. Journal of Evaluation in Clinical Practice, 22:4

[52] Loughlin, M, Wyer,P \& Tanenbaum, S (2016) Teaching by (bad) example - commentary on Jenicek's 'Do we need another discipline in medicine?' Journal of Evaluation in Clinical Practice, 22:4

[53] Jenicek, M. (2015). Do we need another discipline in medicine? From epidemiology and evidence-based medicine to cognitive medicine and medical thinking. Journal of Evaluation in Clinical Practice, 21:6, 1028-1034

[54]Loughlin, M., Lewith, G. \& Falkenberg, T. (2013) Science, practice and mythology: a definition and examination of the implications of scientism in medicine. Healthcare Analysis, 21, 130-145.

[55] Nagel, T. (1986) The View from Nowhere. Oxford: Oxford University Press. 